\title{
Human Resource Management Outsourcing Decision for Small and Medium-sized Enterprises in China
}

\author{
Jing Chu \\ Correspondence: Jing Chu, College of Economics \& Management, Nanjing University of Aeronautics and Astronautics, \\ Nanjing, Jiangsu, 211106, China. Tel: (+86)156-0516-0838. E-mail: chujing_nuaa@163.com
}

Received: May 20, 2016

doi:10.5539/ibr.v9n8p64

\author{
Accepted: May 31, 2016 \\ Online Published: June 16, 2016 \\ URL: http://dx.doi.org/10.5539/ibr.v9n8p64
}

\begin{abstract}
Human resource management (HRM) plays an important role in every enterprise. Nowadays, in China, more and more enterprises, not only large companies, but also small and medium-sized enterprises (SMEs) choose to outsource their HRM activities for economic and strategic benefits. According to the feature of HRM in SMEs, this paper builds a more systematic and practical human resource management outsourcing decision model for SMEs. In this decision model, HRM activities are classified into transaction, profession and strategy levels, and economic benefit, core competence enhancement and risks are taken into consideration. Applying multi-objective intelligent weighted grey target decision method based on combination weighting approach, the decision model can help the enterprise decide which HRM activities should be outsourced in priority sequence. The study proposes a scientific guidance for China's SMEs to make the HRM outsourcing decision.
\end{abstract}

Keywords: combination weighting method, decision making, human resource management outsourcing, multi-objective intelligent weighted grey target decision model

\section{Introduction}

With the further development of economic globalization, the market has entered into a phase full of intense and specialized competition. Because of the limit of internal resources, enterprises have to focus on their core business, while sourcing out non-core business to others who can do it cheaper, faster and better. The outsourcing activities grew over $30 \%$ every year in the last two decades (Kabiraj \& Sinha, 2016). Now, outsourcing has become a pervasive business practice used in a number of organizational functions, such as human resource management (Belcourt, 2006). Human resource management outsourcing is a management mode that enterprises outsource some of the human resource management activities to a third party service provider or service seller for economic and strategic benefits (Greer, Youngblood, \& Gray, 1999). Enterprises undertake HRM outsourcing to reduce cost, achieve better service, gain management flexibility and focus on the core competences (Woodall, Scott-Jackson, Newham, \& Gurney, 2009).

In 2011, four government departments released a document about the definition of SMEs in China. (Ministry of Industry and Information Technology of the People's Republic of China, 2012). Different industries have different criteria on the indicators like practitioners, operating income and total assets when defining SMEs. In the context of Chinese society, compared to large enterprises, SMEs usually haven't reached a certain scale, formed a specific and mature management mode, nor occupied an important place in the market. As the statistic shows, SMEs in China have an average lifetime for no more than 3 years. With the strong desire to live through the economic transition period, SMEs in China are urgent to update their management concepts and find more efficient management modes. The most urgent problem in SMEs is human resource management problem. As the outsourcing market is growing mature gradually, outsourcing has become a good choice for SMEs to deal with the HRM functions.

HRM outsourcing has been well researched in large companies, while is relatively less researched in SMEs. However, for SMEs, how to make the HRM outsourcing decision is usually quite complex. This paper provides a feasible approach for SMEs operators to make the HRM outsourcing decision by building a systematic and practical decision model. With the wide application of HRM outsourcing in SMEs, not only SMEs can improve their management abilities, but also the outsourcing market in China will develop rapidly.

\section{HRM Outsourcing Decision Model for SMEs in China}

\subsection{Selecting the Decision Alternatives}

Many scholars tried to sort HRM functions into several modules. 3P model researches HRM activities from three 
aspects: position, performance, and payment (Lin, 1999). Then, the 3P model has been expanded to a 5P model: position, people, performance, payment, and positive attitude (Liao, 2004). In some enterprises, HRM activities are classified into six modules: human resource planning, recruitment and allocation, training and development, performance management, compensation and benefit management, and employee relationship management. The existing HRM outsourcing decision models usually take these modules as alternatives.

However, compared to large firms, enterprises of smaller scale have higher flexibility, but at the meantime, less liquidity and weaker ability to resist risks, which means improper decision costs more in SMEs. In addition, due to the lack of professional HRM staff in SMEs, it is difficult for them to refine the HRM outsourcing decision and put it into practice. Based on these two reasons, existing HRM outsourcing decision models are not specific enough to meet the demand of SMEs.

To make the decision model more specific and practical, this paper divides every HRM function into three levels, transaction level, profession level, and strategy level. Activities of transaction level are easy to be performed and can be repeated; activities of profession level need to be performed by professional staff; and activities of strategy level are closely related to organization operation, which are difficult for human resource managers. This model helps the enterprise decide which level of which HRM function should be outsourced in priority order. In that way, the enterprise can control risk and reduce the difficulty of implementation. As it is shown in Table 1, this paper divides five HRM functions into 13 decision alternatives.

Table 1. Decision alternatives of HRM outsourcing

\begin{tabular}{|c|c|c|c|}
\hline & Transaction level & Profession level & Strategy level \\
\hline $\begin{array}{l}\text { Recruitment } \\
\& \text { Allocation }\end{array}$ & $\begin{array}{l}\text { Archives management \& } \\
\text { Release recruitment } \\
\text { information }\end{array}$ & Recruitment & $\begin{array}{l}\text { Institution setup \& } \\
\text { Personnel planning }\end{array}$ \\
\hline $\begin{array}{l}\text { Training \& } \\
\text { Development }\end{array}$ & & $\begin{array}{ll}\text { Training design } & \text { and } \\
\text { implementation } & \end{array}$ & Training system planning \\
\hline Performance management & & $\begin{array}{l}\text { Performance appraisal } \\
\text { and feedback }\end{array}$ & $\begin{array}{l}\text { Performance management } \\
\text { system design }\end{array}$ \\
\hline $\begin{array}{l}\text { Compensation \& } \\
\text { Benefit management }\end{array}$ & $\begin{array}{l}\text { Social insurance payment } \& \\
\text { Salary and welfare payment }\end{array}$ & $\begin{array}{l}\text { Compensation and benefit } \\
\text { structure design and calculation }\end{array}$ & $\begin{array}{l}\text { Compensation } \\
\text { design }\end{array}$ \\
\hline Employee relationship management & Labor contracts signing & $\begin{array}{l}\text { Employee communication and } \\
\text { coordination }\end{array}$ & Enterprise culture creating \\
\hline
\end{tabular}

\subsection{Selecting the Decision Indicators}

According to the existing researches, enterprises undertake outsourcing to reduce cost, achieve better service, and focus on core strategy. However, outsourcing generates risks as well (Delmotte \& Sels, 2007). Thus, the decision as to which HRM function should be outsourced is often driven by lots of factors. Transaction cost economics (TCE) and resource based view (RBV) are two main rationales that underpin different decision models theoretically. TCE suggests that outsourcing occurs only when enterprise can achieve lower total cost by transacting with external vendors (Coase, 1937). The RBV together with core competence theory provide another perspective on how to decide which HRM function should be outsourced, the resource of an enterprise is so limited that should be focused on building core competence, while outsourcing the peripheral activities (Pereira \& Anderson, 2012). Most decision models about HRM outsourcing are based on these two rationales. For example, David Lepark and Scolt Snell converge on two dimensions, value and uniqueness, when determining which HRM activity should be outsourced (Lepark \& Snell, 1998). Another decision model is developed by Alan Speaker, he uses a two-by-two typology to classify HRM activities: the type and the strategic value of HRM activities (Klaas, McClendon, \& Gainey, 1999). Domestic scholar Zhilin Hu holds the view that whether a HRM activity should be outsourced or not depends on its benefit-cost ratio and contribution to core competence (Hu, 2004).

Obviously, the views of TCE and RVB take short-term and long-term interests into consideration respectively in HRM outsourcing decision. Short-term interests ensure the financial security, while long-term interests make sure the decision will be good for the enterprise with the long-term development. However, as we all know, benefits come with risks. A proper decision can bring the enterprise expected benefits, at the same time, keep potential risks under control. Thus, this paper suggests that enterprises can make HRM outsourcing decision according to a model of three dimensions: short-term feasibility, long-term expectation and risk controllability, as Figure 1 shows. 


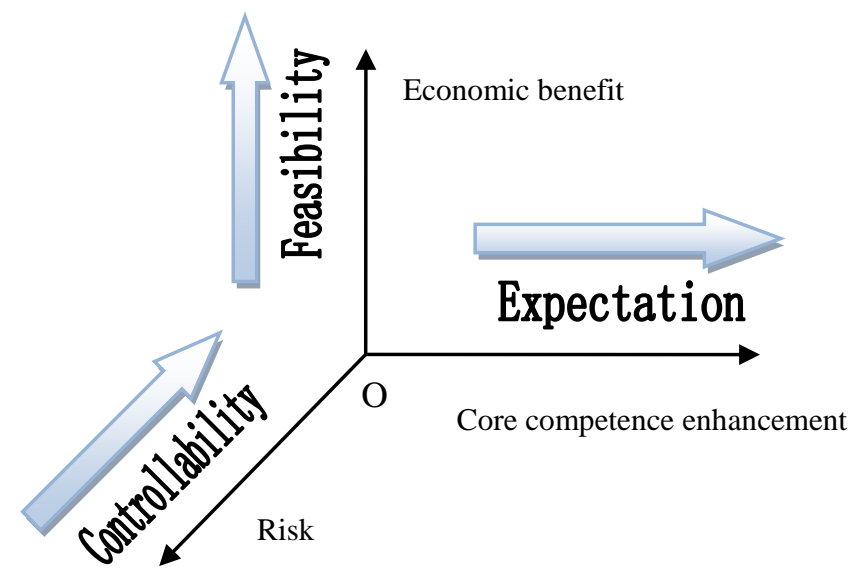

Figure 1. Three dimensions of HRM outsourcing decision model in SMEs

As the three dimensions of this decision model can't be measured directly, some more specific indicators are used to describe them.

Table 2. Decision indicators of HRM outsourcing in SMEs

\begin{tabular}{cl}
\hline Dimensions & \multicolumn{1}{c}{ Indicators } \\
\hline \multirow{3}{*}{ Economic benefit } & Reduce the cost of daily human resource management \\
& $\begin{array}{l}\text { Reduce the economic loss caused by unprofessional management } \\
\text { Reduce the investment in non-core business to control cost expense }\end{array}$ \\
\hline \multirow{3}{*}{$\begin{array}{l}\text { Core competence } \\
\text { enhancement }\end{array}$} & Acquire advanced professional technology, expertise and management concept \\
& Focus on the strategic role of HRM \\
& Improve the adaptability and flexibility of HRM \\
& Improve the communication and justification in organization \\
\hline & Make wrong judgment on vendor's service quality \\
& Lose control of human resource management \\
& Be the obstacles of enterprise learning and innovation \\
& Have culture conflicts with vendor \\
& Employees have resistant emotion \\
& Reveal confidential information
\end{tabular}

\subsection{The Determination of Weights}

Each indicator makes different contribution to the decision making, the importance of indicators is reflected in the weights. Methods of determining weights can be classified into two catalogs, subjective weighting approaches and objective weighting approaches. Subjective weighting approaches, like Delphi and AHP, mainly depend on the knowledge and experience of decision makers, but with great randomness. Objective weighting approaches, like factor analysis and entropy, determine weights by digging the relationship in original data, which can be objective but cannot reflect the preference of decision makers. That means, subjective and objective weighting approaches have their advantages and disadvantages respectively (Jia, Tong, Wang, \& Li, 2016). Therefore, the application of combination weighting method can overcome the limitations of using subjective or objective weighting approach only. This paper introduces the combination weighting method based on AHP and Maximizing Deviation method.

From the point of Maximizing Deviation method, if the performance values of decision alternatives have little differences under an indicator, it means that such an indicator has small impact on the decision making. On the contrary, if the differences among all performance values of decision alternatives under an indicator are obvious, it means such an indicator plays an important role in selecting the best alternative. So, Maximizing Deviation method thinks that the bigger the deviation of the values of decision alternatives under an indicator is, the bigger the weight of the indicator should be (Liang, Zhang, \& Liu, 2015). Extremely, if the value of each alternative has no difference under a given indicator, this indicator has no contribution to the decision making, and its weight should be set to be 0 .

A simple algorithm put forward by Rong Zhang based on the Maximizing Deviation method is used to give objective weight to each indicator (Zhang, SF. Liu, B. Liu, 2007). Let $\eta=\left(\eta_{1}, \eta_{2}, \cdots \eta_{s}\right)$ denote the objective weights of indicators 1 to $\mathrm{s}$, and there are decision alternatives 1 to $m . t_{i k}$ represents the sample value of alternative $i$ under indicator $k$. For the indicator $k$, let $W_{i k}(\eta)$ denote the deviation between the alternative $i$ and all the other alternatives, and let $W_{k}(\eta)$ denote the total deviation among all the decision alternatives in terms of the indicator $k$. Define: 


$$
\begin{gathered}
W_{\mathrm{ik}}(\eta)=\sum_{j=1}^{m} \eta_{k}\left|t_{i k}-t_{j k}\right| \\
W_{K}(\eta)=\sum_{i=1}^{\mathrm{m}} W_{i k}(\eta)=\sum_{i=1}^{m} \sum_{j=1}^{m} \eta_{k}\left|t_{i k}-t_{j k}\right|
\end{gathered}
$$

The weight of indicator $k$ can be obtained as $W_{k}(\eta)$ divided by the total deviation of all indicators. Thus, $\eta_{\mathrm{k}}$ can be expressed as formula (3):

$$
\eta_{k}=\frac{W_{k}(\eta)}{\sum_{k=1}^{s} W_{k}(\eta)}=\frac{\sum_{i=1}^{m} \sum_{j=1}^{m}\left|t_{i k}-t_{j k}\right|}{\sum_{k=1}^{s} \sum_{i=1}^{m} \sum_{j=1}^{m}\left|t_{i k}-t_{j k}\right|}
$$

The subjective weight vector $\theta=\left(\theta_{1}, \theta_{2}, \cdots \theta_{s}\right)$ can be obtained by using AHP method. Commonly, to a certain indicator, if one of its objective weight or subjective weight is equal to 0 , the comprehensive weight of this indicator should be set to be 0 . Based on this, the comprehensive weight can be obtained by normalizing the product of objective weight and subjective weight:

$$
\omega_{k}=\frac{\eta_{k} * \theta_{k}}{\sum_{k=1}^{s} \eta_{k} * \theta_{k}}
$$

The comprehensive weight vector can be expressed as $\omega=\left(\omega_{1}, \omega_{2}, \cdots \omega_{s}\right)$.

\subsection{Multi-objective Intelligent Weighted Grey Target Decision Model}

Except the qualitative models mentioned above, many scholars use quantitative models to deal with the HRM outsourcing problems to make the decision more objective. The existing quantitative models used in HRM outsourcing decision, like AHP and fuzzy comprehensive evaluation ( $\mathrm{Li}, 2007)$, can just sequence the decision alternatives. Multi-objective intelligent weighted grey target decision model is the supplement and improvement of grey target decision model (Liu, Yuan, \& Sheng, 2010). Alternatives may hit the target or miss the target, this method can help decision makers get rid of unsuitable alternatives and sequence the suitable alternatives.

\subsubsection{Define Event Set, Alternative Set, Decision Scheme Set and Decision Objectives}

Suppose there are $\mathrm{n}$ events to research in this problem, which form an event set $A=\left\{a_{1}, a_{2}, \cdots, a_{n}\right\}$. All alternatives could be selected are denoted as $B=\left\{b_{1}, b_{2}, \cdots, b_{m}\right\}$. Set $A$ and set $B$ compose the decision scheme set $S=A \times B=\left\{s_{i j}=\left(a_{i}, b_{j}\right) a_{i} \in A, b_{j} \in B\right\}$. There are $k$ decision objectives, $k=1,2, \cdots, s$.

\subsubsection{Obtain the Effect Sample Matrix of Each Objective According to Experts' Evaluation}

The score standard mainly takes a five-point Likert scale for reference. The occurrence possibility of each indicator is divided into five levels to let managers choose. The score standard is shown in Table 3.

Table 3.Score standard of indicators' occurrence possibility

\begin{tabular}{cc}
\hline Score scope & Evaluation criterion \\
\hline $0 \sim 0.1$ & Strongly impossible \\
$0.2 \sim 0.3$ & Unlikely \\
$0.4 \sim 0.6$ & Neutral \\
$0.7 \sim 0.8$ & Likely \\
$0.9 \sim 1.0$ & Strongly possible \\
\hline
\end{tabular}

The effect sample value of $\mathrm{s}_{i j}$ relative to objective $k$ is denoted as $u_{i j}^{(k)}(i=1,2, \cdots, n ; j=1,2, \cdots, m)$, so the effect sample matrix of the decision scheme set $S$ under the objective $k$ is:

$$
U^{(k)}=\left(u_{\ddot{j}}^{(k)}\right)=\left[\begin{array}{cccc}
u_{11}^{(k)} & u_{12}^{(k)} & \cdots & u_{1 m}^{(k)} \\
u_{21}^{(k)} & u_{22}^{(k)} & \cdots & u_{2 m}^{(k)} \\
\vdots & \vdots & \ddots & \vdots \\
u_{n 1}^{(k)} & u_{n 2}^{(k)} & \cdots & u_{n m}^{(k)}
\end{array}\right]_{\text {? }}
$$

\subsubsection{Set up the Critical Effect Values to Get the Consistent Effect Measurement Matrix}

The objectives can be classified into three kinds, income-based index, cost-based index and fixed index. 
If objective $k$ is an income-based index, the larger the sample value is, the better the result is. Let $u_{i j}^{(k)} \in\left[u_{i_{0} j_{0}}^{(k)}, \max _{j} \max _{j}\left\{u_{i j}^{(k)}\right\}\right]$ be the grey target in terms of objective $k, u_{i_{0} j_{0}}^{(k)}$ is the critical effect value of objective $k$. Define the effect measurement value of income-based index as:

$$
r_{i j}^{(k)}=\frac{u_{i j}^{(k)}-u_{i_{0} j_{0}}^{(k)}}{\max _{i} \max _{j}\left\{u_{i j}^{(k)}\right\}-u_{i_{0} j_{0}}^{(k)}}
$$

If objective $k$ is a cost-based index, the smaller the sample value is, the better the result is. Let $\mathbf{u}_{i j}^{(k)} \in\left[\min _{i} \min _{j}\left\{u_{i j}^{(k)}\right\}, u_{i_{0} j_{0}}^{(k)}\right]$ be the grey target in terms of objective $k, \mathbf{u}_{i_{0} j_{0}}^{(k)}$ is the critical effect value of objective $k$. Define the effect measurement value of cost-based index as:

$$
r_{i j}^{(k)}=\frac{u_{i_{0} j_{0}}^{(k)}-u_{i j}^{(k)}}{u_{i_{0} j_{o}}^{(k)}-\min _{i} \min _{j}\left\{u_{i j}^{(k)}\right\}}
$$

If objective $k$ is a fixed index, the more accurately the sample value falls into the certain interval, the better the result is. Let $\mathrm{u}_{i j}^{(k)} \in\left[A-\boldsymbol{u}_{i_{\mathrm{j}} j_{\mathrm{o}}}^{(k)}, A+u_{i_{j_{0}}}^{(k)}\right]$ be the grey target in terms of objective $k$. If $\boldsymbol{u}_{i j}^{(k)} \in\left[A-u_{i, j_{o}}^{(k)}, A\right]$, denote formula (7) to be the lower limit effect measurement value of the fixed index.

$$
r_{i j}^{(k)}=\frac{u_{i j}^{(k)}-A+u_{i_{0} j_{o}}^{(k)}}{u_{i_{o} j_{o}}^{(k)}}
$$

If $\mathrm{u}_{i j}^{(k)} \in\left[A, A+u_{i_{j_{j}}}^{(k)}\right]$, denote formula (8) to be the upper limit effect measurement value of the fixed index.

$$
r_{i j}^{(k)}=\frac{A+u_{i_{0} j_{o}}^{(k)}-u_{i j}^{(k)}}{u_{i_{o} j_{o}}^{(k)}}
$$

After normalization, to all objectives, the effect measurement value bigger is, the result better is. Thus, define the consistent effect measurement matrix of objective $k$ as:

$$
R^{(\mathrm{k})}=\left(r_{i j}^{(k)}\right)=\left[\begin{array}{cccc}
r_{11}^{(k)} & r_{12}^{(k)} & \cdots & r_{1 m}^{(k)} \\
r_{21}^{(k)} & r_{22}^{(k)} & \cdots & r_{2 m}^{(k)} \\
\vdots & \vdots & \ddots & \vdots \\
r_{n 1}^{(k)} & r_{n 2}^{(k)} & \cdots & r_{n m}^{(k)}
\end{array}\right]
$$

$r_{i j}^{(k)} \in[-1,1]$ is dimensionless, the larger $r_{i j}^{(k)}$ is, the better the result is. If $\mathrm{r}_{i j}^{(k)} \in[0,1]$, hit the target; if $r_{i j}^{(k)} \in[-1,0]$, miss the target.

\subsubsection{Get the Comprehensive Effect Measurement Matrix R}

$$
r_{i j}=\sum_{k=1}^{s} \omega_{k} * r_{i j}^{(k)}
$$

According to formula (9), it's easy to get the comprehensive effect measurement matrix R:

$$
R=\left(\mathrm{r}_{i j}\right)=\left[\begin{array}{cccc}
r_{11} & r_{12} & \cdots & r_{1 m} \\
r_{21} & r_{22} & \cdots & r_{2 m} \\
\vdots & \vdots & \ddots & \vdots \\
r_{n 1} & r_{n 2} & \cdots & r_{n m}
\end{array}\right]
$$

\subsubsection{Make the Decision}

It's easy to tell whether the alternative hits the target or misses the target. The alternatives that miss the target are out of the choice; arrange $r_{i j}>0$ according to the order from small to large, then can get the optimal sequencing of every feasible alternative.

\section{Demonstrated Application}

$\mathrm{X}$ is a medium-sized enterprise in Jiangsu province, China. To survive in the fierce competition, Managers in $\mathrm{X}$ enterprise are considering outsourcing some of its HRM activities instead of performing internally to reduce cost and enhance its core competence. Apply the multi-objective intelligent weighted grey target decision model to help $\mathrm{X}$ 
enterprise make the HRM outsourcing decision. 15 experts and managers are involved to make the decision which HRM activities should be outsourced. Let everyone score the candidate activities according to each indicator, and get the average scores.

\subsection{Define Event Set, Alternative Set, Decision Scheme Set and Decision Objectives}

In this problem, the event is the HRM outsourcing decision of the enterprise X, which means event set $A=\left\{a_{1}\right\}$. The alternatives are HRM activities that could be outsourced, $B=\left\{b_{1}, b_{2}, \cdots, b_{13}\right\} . A$ and $B$ compose the decision scheme $S=\left\{s_{i j}=\left(a_{i}, b_{j}\right) \mid a_{i} \in A, b_{j} \in B, i=1 ; j=1,2, \cdots, 13\right\}=\left\{s_{11}, s_{12}, \cdots, s_{113}\right\}$. The decision making has to take three dimensions into consideration: short-term feasibility, long-term expectation and risk controllability. Each dimension is described by some specific indicators, so there are 14 objectives, $\mathrm{k}=1,2, \cdots 14$.

\subsection{Obtain the Effect Sample Vectors}

Obtain 14 effect sample vectors $U^{(K)}, k=1,2, \cdots, 14$ according to the effect sample value of $s_{i j}$ relative to 14 indicators scored by decision makers.

\subsection{Determining the Indicators' Weights under Each Dimension and Dimensions' Weights}

The sum of indicators' weights under each dimension and the sum of three dimensions' weights are both equal to 1 . Assign the weights by the combination weighting method based on AHP and Maximizing Deviation method, the weights are shown as follow:

$$
\begin{gathered}
\omega^{(1)}=[0.44,0.08,0.48] \\
\omega^{(2)}=[0.15,0.21,0.50,0.05,0.09] \\
\omega^{(3)}=[0.08,0.34,0.12,0.06,0.24,0.16] \\
\omega=[0.21,0.19,0.60]
\end{gathered}
$$

\subsection{Get the Effect Sample Vectors of Three Dimensions}

According to 14 effect sample vectors and the weights of indicators under each dimension, it's easy to get the effect sample vectors of three dimensions.

$$
\begin{aligned}
U^{(1)} & =[0.75,0.60,0.26,0.66,0.33,0.62,0.30,0.80,0.56,0.30,0.85,0.61,0.24] \\
U^{(2)} & =[0.64,0.71,0.51,0.72,0.48,0.73,0.50,0.59,0.63,0.49,0.66,0.54,0.38] \\
U^{(3)} & =[0.19,0.27,0.67,0.37,0.39,0.56,0.52,0.14,0.29,0.57,0.33,0.47,0.69]
\end{aligned}
$$

\subsection{Set up the Critical Effect Values to Get the Consistent Effect Measurement Vectors}

The enterprise can set up the critical effect value according to its expectation to economic benefit and core competence enhancement, as well as its tolerance to risk. Economic benefit and core competence enhancement are income-based indexes, and risk is a cost-based index. The critical effect value can be set between 0 and 1 . The enterprise hopes to have at least neutral possibility to achieve benefit, so let $u_{i_{0}, j_{0}}^{(1)}=u_{i_{0} j_{0}}^{(2)}=0.5$. And it cannot tolerate risks more than neutral possibility, so let $\mathbf{u}_{i_{0} j_{0}}^{(3)}=0.5$. Thus, the consistent effect measurement vector of each dimension is obtained:

$$
\begin{gathered}
R^{(1)}=[0.70,0.30,-0.68,0.45,-0.48,0.33,-0.58,0.86,0.16,-0.58,1,0.32,-0.73] \\
R^{(2)}=[0.60,0.93,0.04,0.98,-0.07,1,-0.02,0.39,0.57,-0.06,0.69,0.19,-0.53] \\
R^{(3)}=[0.86,0.63,-0.48,0.36,0.29,-0.16,-0.06,1,0.58,-0.19,0.46,0.09,-0.54]
\end{gathered}
$$

\subsection{Obtain the Comprehensive Effect Measurement Vector}

According to formula (9), obtain the comprehensive effect measurement vector.

$$
R=[0.78,0.62,-0.43,0.50,0.06,0.16,-0.16,0.86,0.49,-0.25,0.62,0.16,-0.58]
$$

\subsection{Result Analysis}

If effect measurement value is less than 0 , the alternative is out of choice. According to vector $R$, institution setup \& personnel planning, performance management system design, compensation strategy design and enterprise culture creating are not suggested to be outsourced. The suggested outsourcing sequence of the rest activities is: social insurance payment \& salary and welfare payment $>$ archives management \& release recruitment information $>$ recruitment $=$ labor contracts signing $>$ training design and implementation $>$ Structure design and calculation of compensation and benefit $>$ Performance appraisal and feedback $=$ Employee communication and coordination $>$ Training system planning.

In this case, enterprise $X$ is suggested to outsource the HRM activities of transaction level first, and then HRM activities of profession level, while these of strategy level are not suggested to be outsourced. This suggestion is suitable for most 
SMEs in China. Outsourcing HRM activities of strategy level has big effect on organization operation, but usually needs large investment, and can easily cause risks. While outsourcing HRM activities of transaction level can achieve economies of scale, help enterprise focus on core business, and has little possibility to cause risks, but making little contribution to enhancing core competence. For one thing, Chinese economy is in the critical period of transition, SMEs are not willing to take big risks when making decisions. For another, outsourcing HRM activities of strategy level puts forward higher requirements to vendors. However, it's quite difficult for SMEs to find a satisfying vendor in the immature outsourcing market.

\section{Conclusion}

This paper analyzed the characters of HRM outsourcing decision making in SMEs, reviewed the existing HRM outsourcing decision models, and then applied the multi-objective intelligent weighted grey target decision model based on combination weighting method to the HRM outsourcing decision making in SMEs. And the demonstrated application shows the rationality and significance of this model. With the development of outsourcing market and the updating of HRM concepts in SMEs, HRM outsourcing will be adopted by more and more SMEs. This study provides a systematical and practical method for China's SMEs to make the HRM outsourcing decision.

As the result of demonstrated application shows, enterprise X prefers to outsource the HRM activities of transaction level. Like enterprise X, most SMEs in China are in a dilemma that they do not have the ability to undertake the HRM activities of strategy level internally, while outsourcing isn't a good choice either. To perform the HRM activities of strategy level well, several suggestions are proposed. (a) For SMEs, consider human resource management in the strategic perspective, and develop own HRM talents. HRM should be closely related to the operation strategy in an enterprise, and the ability to perform strategic HRM activities internally makes great contribution to enhancing the enterprise's core competence. (b) For HRM vendors, improve the professional quality and service attitude, and transfer their business to the HRM activities of strategy level. Although not many enterprises choose to outsource their strategic HRM activities now, it will become the development trend absolutely. Vendors who make good preparation will have the chance to stand out from the fierce competition. (c) For government, improve law and regulation to protect the legitimate interests of enterprises and vendors. One reason SMEs don't outsource their strategic HRM activities is that the imperfect law and regulation cannot protect their benefit when facing conflict with vendors. In China, the improvement of relevant law and regulation has big effect on accelerating the growth of HRM outsourcing market.

\section{References}

Belcourt, M. (2006).Outsourcing: The benefits and the risks. Human Resource Management Review, 16(2), 269-279. http://dx.doi.org/10.1016/j.hrmr.2006.03.011

Coase, R. H. (1937). The nature of the firm. Economica, 4(16), 386-405. http://dx.doi.org/10.1111/j.1468-0335.1937.tb00002.x

Delmotte. J., \& Sels, L. (2008). HR outsourcing: threat or opportunity? Personnel Review, 37(5), 543-563. http://dx.doi.org/10.1108/00483480810891673

Greer, C. R., Youngblood, S. A., \& Gray, D. A. (1999). Human resource management outsourcing: the make or buy decision. Acad Manage Exec, 13(3), 85-96. http://dx.doi.org/10.5465/AME.1999.2210317

$\mathrm{Hu}, \mathrm{Z}$. L. (2004). Research on the model of human resource outsourcing (Master's thesis, Wuhan University, Wuhan, China). Retrieved from http://d.wanfangdata.com.cn/Thesis/Y631047

Jia, L. T., Tong, Z. X., Wang, C. Z., \& Li, S. B. (2016). Aircraft Combat Survivability Calculation Based on Combination Weighting and Multiattribute Intelligent Grey Target Decision Model. Mathematical Problems in Engineering, 2016(8), 1-9. http://dx.doi.org/10.1155/2016/8934749

Kabiraj, T., \& Sinha, U. B. (2016). Strategic outsourcing with technology transfer under price competition. International Review of Economics and Finance,2016.http://dx.doi.org/10.1016/j.iref.2016.02.016

Klaas, B. S., McClendon, J., \& Gainey, T. (1999). HR outsourcing and its impact: the role of transaction costs. Personnel Psychology, 52(1), 113-136. http://dx.doi.org/10.1111/j.1744-6570.1999.tb01816.x

Lepak, D. P., \& Snell, S. A. (1998). Virtual HR: strategic human resource management in the 21st century. Human Resource Management Review, 8(3), 215-234. http://dx.doi.org/10.1016/S1053-4822(98)90003-1

Li, F. L. (2007). Decision making for human resource management outsourcing based on AHP and fuzzy comprehensive evaluation method. Journal of Hebei University of Engineering (Social Science Edition), 24(4), 18-21. http://dx.doi.org/10.3969/j.issn.1673-9477.2007.04.006

Liang, W., Zhang, X. L., \& Liu, M. F. (2015). The Maximizing Deviation Method Based on Interval-Valued 
Pythagorean Fuzzy Weighted Aggregating Operator for Multiple Criteria Group Decision Analysis. Discrete Dynamics in Nature and Society, 2015, 1-15. http://dx.doi.org/10.1155/2015/746572

Liao, J. Q. (2004). 5P model-A new taxonomy of human resource management. Chinese Journal of Management, 1(1):71-75.http://dx.doi.org/10.3969/j.issn.1672-884X.2004.01.018

Lin, Z. Y. (1999). Specification of human resources management in small and medium-sized enterprises. Human Resource Development of China, 12, 15-17. http://dx.doi.org/10.16471/j.cnki.11-2822/c.1999.12.004

Liu, S. F., Yuan, W. F., \& Sheng, K. Q. (2010). Multi-attribute intelligent grey target decision model. Control and Decision, 25(8), 1160-1163. http://dx.doi.org/10.13195/j.cd.2010.08.42.liusf.001

Ministry of Industry and Information Technology of the People's Republic of China. (2012). Notification of issuing classification criteria of small and medium-sized enterprise. Retrieve from http://www.miit.gov.cn/n1146285/n1146352/n3054355/n3057278/n3057286/c3592332/content.html

Pereira, V., \& Anderson, V. (2012). A longitudinal examination of HRM in a human resources offshoring (HRO) organization operating from India. Journal of World Business, 47(2), 223-231. http://dx.doi.org/doi:10.1016/j.jwb.2011.04.009

Woodall, J., Scott-Jackson, W., Newham, T., \& Gurney, M. (2009). Making the decision to outsource human resources. Personnel Review, 38(3), 236-252. http://dx.doi.org/10.1108/00483480910943313

Zhang, R., Liu, S. F., \& Liu, B. (2007). The general algorithm based on maximizing deviation weighting method. Statistics \& Decision, 2007(24), 29-31. http://dx.doi.org/10.13546/j.cnki.tjyjc.2007.24.030

\section{Copyrights}

Copyright for this article is retained by the author(s), with first publication rights granted to the journal.

This is an open-access article distributed under the terms and conditions of the Creative Commons Attribution license (http://creativecommons.org/licenses/by/3.0/). 